\title{
SOIL CARBON: POLICY AND ECONOMICS
}

\author{
GREGG MARLAND ${ }^{1}$, BRUCE A. MCCARL ${ }^{2}$, UWE SCHNEIDER ${ }^{3}$ \\ ${ }^{1}$ Oak Ridge National Laboratory, Oak Ridge, TN, U.S.A. \\ ${ }^{2}$ Texas A\&M University, College Station, TX, U.S.A. \\ ${ }^{3}$ Iowa State University, Ames, IA, U.S.A.
}

\begin{abstract}
.
Agricultural soils provide a prospective way of mitigating the increasing atmospheric concentration of $\mathrm{CO}_{2}$. A number of agricultural practices are known to stimulate the accumulation of additional soil carbon and early indications are that some might sequester carbon at relatively modest costs with generally positive environmental effects. We discuss, under 10 themes, policy and economic issues that will determine whether programs for sequestration of carbon in agricultural soils can succeed. The issues involve contexts for implementation, economics, private property rights, agricultural policy, and institutional and social structures. Ultimately, success will depend on the incentive structure developed and the way in which carbon sequestration is integrated into the total fabric of agricultural policy.
\end{abstract}

\section{Introduction}

Agricultural soils are among the planet's largest reservoirs of carbon and hold potential for expanded carbon sequestration. Decreasing carbon stocks in the biosphere, including agricultural soils, have historically been a net source of $\mathrm{CO}_{2}$ emissions to the atmosphere, but this process is amenable to reversal and net carbon flows from the atmosphere to the biosphere are feasible. Within the context of the United Nations Framework Convention on Climate Change (U.N., 1992), the Kyoto Protocol (1998), and subsequent discussions, a number of features make carbon sequestration on agricultural lands (defined broadly to encompass forestry lands) an attractive strategy for mitigating increases in atmospheric concentrations of 
greenhouse gasses. Certainly the Kyoto Protocol holds open the possibility that interests outside of the agricultural sector may approach those in the agricultural sector to trade emissions permits and credits. Emitters with high emission reduction costs could pay others to reduce net greenhouse gas emissions instead of substantially reducing emissions themselves.

Papers in this special issue consider the overall question of carbon sequestration in agricultural soils. We consider the policy and economic dimensions of the question. We present discussion of the topic as a system of points organized around 10 themes.

- The Kyoto Protocol and the context for managing agricultural soil carbon

- Soil sequestration related agricultural practices to be encouraged

- Externalities and indirect market impacts

- Saturation, longevity of agricultural carbon, and carbon retention

- Private property rights

- Incentive system design and targeting

- Soil carbon as part of a more complete agricultural response agenda

- Farm income supports and carbon sequestration

- Practical economics

- Other considerations

\section{Ten Themes for Consideration}

\subsection{THE KYOTO PROTOCOL AND THE CONTEXT FOR MANAGING AGRICULTURAL SOIL CARBON}

The United Nations Framework Convention on Climate Change (UNFCCC) defines as its objective the "stabilization of greenhouse gas concentrations in the atmosphere at a level that would prevent dangerous anthropogenic interference with the climate system." In order to give substance to this objective, the Parties to the UNFCCC held a meeting in Kyoto, Japan, in December 1997, creating a Protocol intended to provide 
binding limits on greenhouse gas emissions and begin the process of limiting the atmospheric concentrations of greenhouse gases. Most observers recognize (e.g. Bolin, 1998; Wigley, 1998) that, if ratified, the Kyoto Protocol will provide only the beginning step in this process. The Protocol requires ratification by at least 55 countries, including countries responsible for at least 55\% of the 1990 carbon dioxide emissions from those countries listed in Annex I of the UNFCCC. As of October 2000, 30 countries, none of them from Annex I, had ratified the Protocol.

A number of concepts arise in the protocol that are relevant to the soil sequestration strategy. We cover them under the topics: eligibility of sinks, treatment of soils, international trading, verification, leakage, and baselines.

\section{Eligibility of sinks}

Although the prospect of implementing the Kyoto Protocol raises many complex issues, the Protocol does establish international concurrence on some basic ideas and principles. For example, the Protocol recognizes that net emissions may be reduced either by decreasing the rate at which greenhouse gases are emitted to the atmosphere or by increasing the rate at which greenhouse gases are removed from the atmosphere using sinks. Our focus here is on agricultural soils as a sink. Even without ratification the Protocol helps to define this setting.

The Kyoto Protocol clearly establishes credits for carbon sinks in Article 3.3. Three principles appear to underlie the sink provisions in the protocol and supporting documents. First, credits are to be limited to activities undertaken purposefully. Second, credits are to be granted only for those items that could be accurately and reliably measured. Third, counties are not to be allowed to meet their full commitment through sink enhancement, emission reductions must also be pursued.

\section{Treatment of Soils}

In terms of sinks, the Protocol permits credits for a limited list of activities (Article 3.3) while making it possible for additional activities to be added to this list later (Article 3.4). The Article 3.3 sinks involve afforestation and reforestation since 1990, and prescribe debits for deforestation. However, even there the 
role of forest soils is somewhat ambiguous. The Protocol does not clearly indicate that soils are part of the forest. In fact, the Protocol fails to define "forest", "afforestation", and "reforestation". The Intergovernmental Panel on Climate Change recently prepared a Special Report on Land Use, Land Use Change, and Forestry (IPPC, 2000) that explores these and other matters. That report generally does assume that forest soils should be considered as part of the forest.

Agricultural soils are treated in Article 3.4 but only as a possible item for future inclusion. Specifically, the Protocol states that the Conference of the Parties will "decide upon modalities, rules and guidelines as to how, and which, additional human-induced activities related to changes in greenhouse gas emissions by sources and removals by sinks in the agricultural soils and the land-use change and forestry categories shall be added to, or subtracted from, the assigned amounts ...". Simply stated, sequestration in agricultural soils is not now permitted to produce carbon sequestration credits under the Kyoto Protocol, but the door is left open for its addition. Negotiations are ongoing as of October 2000 to clarify coverage.

\section{International Trading}

Sinks are not only relevant within a country, to offset its own emissions. The Protocol establishes the principle of international emission permit trading, which at least partially extends to sinks. Article 6 discusses Joint Implementation, whereby one Annex I country ${ }^{1}$ can pursue projects in another Annex I country and use the carbon benefits toward its own emissions commitments. Article 12 discusses the Clean Development Mechanism, under which projects can be sponsored by an Annex I country in a non-Annex I host. Article 17 discusses trading of emissions credits among Annex I countries. Article 6 specifically mentions "removals by sinks" but this language is missing from Article 12 and coverage needs to be established. Transfer of emissions credits under either Article 6 or Article 17 would not create additional global emissions permits. What appears in the accounts of one party must be subtracted from the other. Transfer of emissions credits under Article 12 would create additional global emissions permits since a country with emissions restrictions

1 The Framework Convention on Climate Change lists in Annex I those developed countries and countries with economies in transition that should adopt practices to limit emissions of greenhouse gases. Countries not specifically listed in Annex I, developing countries, have no such commitments. Appendix B of the Kyoto Protocol 
would obtain additional emissions permits from a country without such.

An issue open to discussion with respect to international trading is the allocation of responsibility for failure to sequester carbon. Does responsibility fall to the buyer or the seller? Sequestration in a non-Annex I country under Article 12 raises additional questions. Presumably this sequestration would be undertaken under a defined contract and the sponsoring country would receive emissions permits as carbon was sequestered in the host country. After expiration of the contract, however, the host country would have no emissions limits under the Kyoto Protocol and the question is whether there is any liability if the sequestered carbon is subsequently released. Strategies for renting emissions permits are poorly developed but are beginning to be discussed.

There are a number of related concerns about international leakage under a system in which some, but not all, countries participate. Some examples are described under the externalities and indirect market impacts theme below.

\section{Monitoring and Verification}

A recurring theme in the Kyoto Protocol is monitoring and verification of carbon emissions and sinks. Potential sinks must somehow be internationally certified with changes in carbon stocks monitored. We will not discuss verifiability at length here, as it is the subject of another paper in this volume (Post et al., this issue). What is of particular importance here is that the Kyoto Protocol includes a variety of mechanisms that permit, and would surely stimulate, trading in carbon emissions permits. Carbon sequestered by one Party could be used to offset emissions in another sector of the national economy (and thus help to meet national commitments under the Kyoto Protocol) or it could be traded or sold to a Party in another country to use in fulfilling its national commitments. In order for a viable market in carbon credits to develop there needs to be a commodity that can be clearly identified and reliably and consistently measured in a country wide setting, not just on a project by project basis.

We also note the possibility that the quantity of carbon credits generated by an endeavor might depend

lists nearly the same countries and provides quantitative limits for greenhouse gas emissions. 
on the uncertainty of sequestration achievement. For example, Canada (1998) has outlined a proposal in which the amount of carbon sequestered by a mitigation measure would be reported along with the uncertainty in this measurement. Credits could be claimed only to the extent that there was $95 \%$ certainty in the amount of carbon sequestered. Under this procedure, the greater the uncertainty, the lower the mitigation credit that could be claimed in order to be $95 \%$ confident that the achievement was indeed at or above the credited amount. ${ }^{2}$

Leakage

An important concept in terms of carbon credits for sinks is that of leakage. Much of the implementation of carbon sinks will occur through specific carbon enhancement projects. When a project is implemented it may stimulate carbon gains through its own activities, but there is the possibility of offsetting carbon losses through changes in activity outside of the project focus area. For example, carbon sequestration endeavors involving transfer of land from agriculture to forestry might stimulate substantial countervailing land transfers out of forestry, thus offsetting the carbon gains. Such losses are called leakage.. Carbon credit projects will need to account for leakage due to altered economic activity in other parts of the economy. Countrywide accounting may sometimes be required. Furthermore, in international carbon trading, the accounting system will need to consider leakage in the source and host countries. However, the leakage issue is further complicated by the fact that some changes in carbon stocks are reportable under the Kyoto Protocol while others are not.

Baselines

Finally, the Protocol raises the issue of baselines. Most notably, under Article 12 emissions credits are required to arise from "reductions in emissions that are additional to any that would occur in the absence of certified project activity". This would require that countries not only monitor and verify the carbon that has been sequestered, but that they measure a baseline of carbon that would have been sequestered without the

2 For example, if the measured value is $+/-5$ (with $95 \%$ confidence), the target would have to be set at 50 to be $95 \%$ confident that the result was at least 45 , but the target would have to be at 50 to be $95 \%$ confident of reaching 40 if the measured value is $+/-10$. 
project. Measurement of carbon stock changes along the path-not-traveled might rely on modeling or control plots. In either case, countries would have to distinguish between what did happen and what would likely have happened. Baselines are likely to be an issue under Article 3.4 of the Protocol as well.

\subsection{SOIL SEQUESTRATION RELATED AGRICULTURAL PRACTICES TO BE ENCOURAGED}

A variety of land-management practices might be encouraged if increasing the agricultural and forestlands carbon soil stock could earn credit toward national emissions targets. This is the subject covered by Metting et al., this issue, but we list a sample of such practices for the sake of illustration (Lal et al., 1998 present a more extensive list). Some of these practices would increase the amount of carbon stored, either above and/or below ground, while others would decrease the loss of carbon from the biosphere.

1. Reduced tillage

2. Restoration of degraded lands

3. Retirement of agricultural lands into permanent grass cover,

4. Increased forested area with conversion of land from agricultural uses

5. Management of residues in agricultural harvests.

A number of forest related strategies are also possible; such as longer forest rotations, improved management of existing forests, carbon retention enhancing forest harvest practices, and better management of reforested areas.

Only item 4 above, and other afforestation and reforrestation activities, appear eligible for emission-reduction credits under the current phrasing of the Kyoto Protocol. Article 3.4 suggests the Parties may add any or all of the other items in the list at some future time.

\subsection{EXTERNALITIES AND INDIRECT MARKET IMPACTS}

Pursuit of soil carbon sequestration may lead to a number of possible gains or losses in other sectors of 
the economy. A term economists use to identify the non-market portions of these effects is externality. Externalities are the effects that an action designed to achieve a particular aim has on the welfare of nontarget individuals. An externality might be positive; for example, a program to increase carbon sequestration by reducing tillage intensity might also reduce erosion, benefiting those who need to dredge waterways. Negative externalities can also arise. For example, in some regions, adoption of reduced tillage is accompanied by increased pesticide usage which might increase pesticide runoff and have negative water quality impacts. Indirect market impacts may also be realized where, for example, increased carbon sequestration may lead to lower food production and higher food prices.

Pursuit of carbon sequestration policies can have a number of co-benefits or positive externalities. In a recent study, McCarl et al. (1997) examined the effects of higher energy prices, caused by a Kyoto-Protocol-motivated system to limit carbon emissions and permit emissions trading among emitters. They found that higher energy prices stimulated widespread expansion of reduced tillage. In turn this led to a reduction in soil erosion. A number of the costs of erosion - lower water quality, disturbed ecology, increased sedimentation, etc. would be reduced by the spread of conservation tillage. Thus, a policy based on carbon emissions or sequestration might well benefit a number of erosion-affected areas and groups not originally the target of the policy. Other types of positive impacts that could occur include:

1. Reduced tillage could increase soil organic matter content, increasing soil water-holding capacity and reducing the need for irrigation water;

2. Expanded conversion of agricultural lands to grasslands or forests could support wildlife populations;

3. Reduced soil disturbance and, possibly, diminished use of fertilizer could alter the volume and chemical content of runoff from agricultural lands. This would in turn affect water pollution, water quality, and the general ecology of streams, rivers, lakes, and aquifers. Such alterations might improve the characteristics of the waters in these regions for use by non-agricultural water consumers.

Along with the possibility of non-market externalities, there is the possibility of market-based impacts on 
groups that are not the target of the program. For example, Adams et al. (1992) and McCarl (1998) show that programs designed to move agricultural lands into forestry could have deleterious effects on the traditional forest sector. These could lead either to deforestation of traditional parcels or to reduced levels of management, either of which would lessen carbon sequestration and offset some of the total amount of carbon being sequestered. Similarly, Marland and Schlamadinger (1997) have showed that carbon sequestration in forests can change the flow of forest products, leading to substitution of alternate products with different energy-intensity, and large implications for the consumption of fossil fuels. Substitution of different products or of products from different sources could occur in the agriculture sector, for example if carbon sequestration efforts changed the productivity of cotton crops. Here is a short list of other possible indirect market impacts:

a. Use of agricultural lands for carbon sequestration could compete with their use for traditional food and fiber production. The result might be decreased food and fiber production; increased consumer prices for crops, meat and fiber; and decreased export earnings from agriculture.

b. Any soil sequestration projects that rely on additional nitrogen fertilizer can cause substantial offsets in total greenhouse gas emissions due to carbon released in fertilizer manufacture and nitrous oxide releases from fertilized fields.

c. Reductions in food production in some countries, due to tradeoffs with carbon programs, might lead to increased agricultural land development through deforestation or grassland conversion in other unregulated countries, leading to higher emissions.

d. Increased availability of wood might encourage use of renewable, biomass fuels or development of other new markets for renewable materials.

Many other indirect impact cases could be cited. The basic point is that there could be both positive and negative indirect environmental and economic effects from policies and projects intended to increase carbon sequestration. This implies that evaluation of programs and projects needs to widely consider possible effects to capture the indirect implications and leakage estimates. 


\subsection{SATURATION, LONGEVITY OF AGRICULTURAL CARBON, AND CARBON RETENTION}

The soil is not an infinite sink for carbon sequestration. Soil absorbs and fixes carbon until it reaches a new steady-state that reflects the new management environment. Over time the rate of net carbon gain decreases and when the new equilibrium is attained the carbon content saturates. Thus, soil sequestration of carbon can decrease net emissions only for a limited amount of time.

Soil carbon is also volatile and changes in practices can cause the soil to quickly revert to a lower carbon state (i.e. a reversion to conventional tillage quickly dissipates carbon gains). Thus, current carbon gains also increase the potential of the soil to become a future emissions source. This raises a policy design issue. In particular, if a subsidy for reduced tillage expires, farmers may revert to conventional tillage, thereby reducing or eliminating the carbon gains. A big question is: Will the incentives designed both get the carbon into soils initially and then keep it there? This is also an issue with respect to afforestation. A recent study by McCarl (1998) concluded that afforested land converted under a carbon-based subsidy program would revert back to agriculture after one forest rotation, unless the program was somehow designed to prohibit harvest or to require that the land remain in forest.

If sequestered carbon becomes a commodity that can be saved or sold, there would presumably be a system of both credits and debits. Credits could be gained for carbon sequestered but there must be subsequent debits if the carbon is later released. Thus, a landowner could sell emission credits when carbon is sequestered, but would then be bound either to provide long-term stewardship, retaining that sequestered carbon, or to bear the cost of emissions when the carbon is released. The Kyoto Protocol has led some to introduce the term "Kyoto Forests" for potential qualifying forested lands that sequester carbon. In the same vein one can envision "Kyoto Farms" where carbon is stored in soils under some long-term obligation. A similar, but different, set of concerns arises if the "Kyoto Farm" is in a country that does not have emissions limits.

Conversion of land from agriculture to forest raises a leakage issue regarding the traditional forest 
sector. The McCarl (1998) modeling study also found substantial countervailing movements of traditional forest land to agriculture when afforestation was subsidized This points out the potential importance of comprehensive project accounting, which accounts for leakages that offset credits. Again, there is a greater problem if the deforestation is stimulated in a different country, especially one without national emissions limits. There is also a time-dependency problem, because reforestation of a parcel of land takes up much less carbon in a given year than would be released by deforestation of a similarly-sized parcel.

The extent of leakage from offsetting strategies will depend on the tax, regulatory, and incentive schemes that countries adopt to try to meet national objectives. Also, leakage accounting may be biased if there is an uneven treatment of carbon stocks within the Protocol. A literal interpretation of the Protocol text and implementation of Article 3.4 might require that national accounts capture deforestation, but not require reporting of, for example, conservation tillage practices discontinued or grasslands plowed.

The potential for expanding agricultural carbon sinks in the face of the volatile nature of future carbon releases when land management changes, raises yet another policy consideration. Agriculture, with its possibilities for change in tillage practice and/or afforestation, offers a near-term way of reducing net carbon emissions, but sequesters carbon that may be released at a future time. However, an essential question is whether this might provide a way of reducing costs for current compliance while awaiting major technological breakthroughs that would substantially reduce future greenhouse gas emission reduction costs. Agriculture may provide a low-cost option bridging to an even lower-cost set of options in the future, even if the sequestered carbon is lost in 20 to 40 years.

There is also the risk that soil carbon holding capacity may diminish as the climate warms, because there is a negative relationship between higher temperatures and the organic matter content of soils. However this effect may be offset by the consequences of increased plant growth.

\subsection{PRIVATE PROPERTY RIGHTS}

As argued in McCarl (1998), embarking on the road toward enhanced carbon sequestration poses 
challenging policy questions regarding private property rights. Adoption of enhanced soil carbon sequestration strategies is not useful if offset by movement toward less carbon friendly systems on other lands or in future times. For example if carbon programs:

a. Start converting land from agriculture into forestry, there may be a need to insure that these movements are not offset by countervailing movements to agriculture from traditional forestry;

b. Make alterations in grassland stocks through, for example, an expansion of conservation reserve program area, there may be a need to insure that pre-existing grasslands and wetlands are not broken out into tilled uses;

c. Pay some farmers to adopt improved conservation tillage, there may be a need to insure that other farmers, who are not being paid, do not revert to more intensive tillage.

Each of these examples contains a prevention or taxation action that would be directed toward a land use decision by those outside of the program, in effect modifying the way they may act in the future with respect to their property. All of these appear to be major property rights issues altering land use options.

\subsection{INCENTIVE SYSTEM DESIGN AND TARGETING}

Today many carbon-enhancing alternatives are known and available to farmers. However, many cases exist where farmers, acting in their own best interests, have not chosen to adopt such practices. Obstacles to such adoption are: a) incomplete information about the consequences of the option; and b) inferiority of the practice relative to existing opportunities from the standpoint of the farmer's preferences. Possible ways to promote such adoption are to expand distribution of information, provide practice-related incentives, and regulate compliance. The information and regulatory approaches will not be discussed here; rather we concentrate on the incentive approach.

The basic argument for incentives is that producers are not using the practices because they are inferior to existing opportunities, given the farmer's reward system. One way of correcting inferiority involves a 
direct economic incentive, perhaps in the form of a carbon price arising through either: a) government subsidies or b) a private market stimulated after a regulatory total emissions cap is applied. Recent work by Antle (2000) and Antle and Mooney (1999) elaborates. Incentive systems may also need to recognize that farmers do not seek only to maximize profits. In particular:

1. Risk often increases when less tillage-intensive practices are adopted in the place of conventional tillage, because of such factors as soil temperature interrelationships with tillage or weed control practices (see Klemme (1985), Williams et al. (1990), or Epplin and Al-Sakkaf (1995)). Farmers who are highly risk averse may avoid adopting practices that increase risk even if they increase carbon sequestration and profitability. This may be particularly true for older farmers who are not willing to bear the risk of changing management practices toward the end of their career. Farmers with limited resources may also be more risk averse. Incentives in the form of risk managing insurance may be needed to facilitate adoption.

2. Management requirements are likely to be more demanding when less tillage-intensive practices are adopted. Farmers may be unwilling to adopt practices that require substantially more critical management activities. This again may be more characteristic of older farmers or farmers with limited resources.

3. Tillage practices, once adopted, have to remain in use for a long time if carbon sequestration gains are to be realized and maintained. Farmers may be unwilling to take on such long-term commitments and it may be difficult to pass the liability on from farmer to farmer when farm ownership changes. Leasing arrangements may also create obstacles. Contract terms and liability for discontinuing carbon-preserving practices need to be worked out.

4. Some farmers are motivated by a stewardship role in terms of the soil and the environment. One may find that farmers holding this attitude might adopt soil-conserving techniques more readily than would others.

Targeting is also an important component of incentive design. An agricultural soils based carbon 
sequestration program has much in common with the long history of agricultural erosion programs. Targeting has been a major concern in such programs. In particular, policy makers would likely try to provide incentives to those who would modify their behavior and sequester the most cost effective carbon. However achievement of such targeting may be difficult. In particular, incentives designed to keep land in forestry might end up paying landowners who had no real intention of ever moving land out of forestry. Soil carbon sequestration represents a non-point phenomenon where the carbon is widely distributed across the landscape. Monitoring and targeting of compliance in such a setting has proven to be costly at times and a difficult targeting exercise. A review of the history and current status of such programs would be an important exercise to pursue in incentive system design (for example see Magleby et al (1995); Pierzynski et al. (1994); and Trimble and Crosson (2000)).

\subsection{SOIL CARBON AS PART OF A MORE COMPLETE AGRICULTURAL RESPONSE AGENDA}

Agriculture can respond to a greenhouse gas emission reduction effort in a number of ways. In particular, there are at lease five ways in which agriculture might be affected by greenhouse gas mitigation efforts and emission trading markets:

1. Agriculture contributes to emissions of greenhouse gases to the atmosphere by releasing substantial amounts of methane, nitrous oxide, and carbon dioxide. Consequently, agriculture may need to reduce emissions and there may be cost effective options involving actions such as reducing fertilizer use, altering livestock feeding, reducing rice acreage, etc.

2. Agriculture provides a potential means for mitigating emissions by offering opportunities for enhancing carbon sinks.

3. Agriculture may be able to produce biofuels as an alternative source of fuel to displace fossil fuel combustion.

4. Agriculture may find itself operating under policies designed to reduce global greenhouse gas emissions and that influence agricultural input and output prices. 
5. Products from the forest sector compete in the market with other, often more energy-intensive, products like concrete, glass, and steel. Policies inspired by the Kyoto Protocol may change the demand for such products.

Policies that are agriculturally oriented and directed toward net greenhouse gas emission reduction need to consider the total effect of all of these roles and the comparative attractiveness of carbon sequestration versus other strategies. Recent work by Schneider (2000) and McCarl and Schneider (2000b) shows soil sequestration is attractive in this more general response arena.

\subsection{FARM INCOME SUPPORTS AND CARBON SEQUESTRATION}

Historically, U.S. agriculture has received extensive public subsidies in the form of price and income supports. At times in the late 1980s or early 1990s the total cost of the farm program was half or more of estimated total U.S. net farm income. For a number of years the U.S. spent $\$ 10-15$ billion on agricultural farm programs. In the mid 1990s the U.S. began phasing out the agricultural farm program, with farm subsidies reduced to $\$ 5-6$ billion, but by the end of the decade they reached near record levels of \$16-22 billion. Those end of decade increases were implemented through changes in disaster payments and expansion of the fixed payments per acre under the 1995 farm program. The farm program is up for renewal in the near future, with a redefinition of the nature of the subsidy program likely.

From an economic viewpoint there are several justifications for the continuation of public subsidies to agriculture. Many say that farm subsidies are needed because the farm industry has inherently low incomes and that there is a need to preserve that industry. There are several forces that have influenced changes in agricultural incomes. Developing technology has caused the supply of food to grow faster than the total demand for food, and this has resulted in declining agricultural prices and farm income. Much of the new agricultural technology has been developed with public funds and there is an argument that the public should subsidize agricultural producers to make up for the effects of the technological shifts and income losses caused by this research funding. Today, in real terms, total income in the agricultural sector is somewhat less 
than 80 percent of what it was 25 years ago. Consumer food prices remain low even in the face of growing population. This has caused out-migration from agriculture and concern over whether society should subsidize producers to stay in the agricultural business. In addition, there are food security issues that have been used to justify agricultural subsidies.

The greenhouse gas sequestration aspects of the Kyoto Protocol raise interesting new possibilities for income supports in agriculture. Most agricultural production faces what economists call an inelastic demand curve. People will not eat a great deal more even if food costs less; so increased production often leads to declining prices.

However, producing feedstocks for the energy market would probably place agriculture as a fairly small player producing against what economists call an elastic demand curve. Such a market would not lead to such large price reductions when agricultural production of energy crops is expanded. Production against such an elastic demand curve would tend to favor producers, yielding net farm-income benefits, as opposed to the consumer benefits that have arisen under the technological advances up to now. This situation could provide justification for a new breed of farm programs, with funding based on energy and carbon sequestration justifying payments to agriculture beyond the traditional arguments that, to some extent, have worn out their welcome in the budget arena.

Even without income support, improved markets for renewable, fuel feedstocks and carbon emissions permits could provide a new source of farm income. A problem with accepting payment for carbon sequestered is that, as pointed out above, carbon sequestration cannot continue forever because soil carbon will eventually approach a new steady state. As carbon accumulates the landowner accumulates an increasing responsibility for stewardship and, potentially, increasing financial liability if the carbon is subsequently released.

\subsection{PRACTICAL ECONOMICS}

From a practical standpoint there are a number of economic questions about carbon sequestration that 
need to be raised in terms of public policy and expected adoption. For example, are the comparative costs of carbon sequestration in agriculture low enough that they would be competitive in an emissions trading market, where non-agricultural interests could buy carbon sequestration credits from agricultural or other interests? Anecdotal evidence seems to suggest that this is the case, but the price vs. quantity schedule for agricultural carbon credits is not clear, nor is the nature of non-agricultural demand. McCarl (1998) and McCarl and Schneider $(1999,2000 a)$, among others, computed that the cost of some opportunities for agricultural sequestration of carbon was at or below thirty dollars per ton of carbon, while recent work by Schneider (2000) finds that carbon sequestration is attractive at low prices. Recent studies by The President's Council of Economic Advisors (1998), the Energy Information Administration of DOE (1998), and by economists as represented by Manne and Richels (1998) and Weyant and Hill (1999), have produced a wide range of estimates for the cost of carbon emissions reductions in other sectors of the economy. The range of costs depends very much on the trading regime permitted, i.e. the extent to which emissions credits will be traded internationally and which countries will participate. It also depends on the rate at which policies are implemented. If sequestration in agricultural soils provides low-cost carbon emissions credits, then there certainly will be room for a market where incentives large enough to stimulate behavioral changes in agriculture will be offered to producers.

A total evaluation of the agricultural soil alternative needs to consider the aggregate price and production effects that a market in carbon emissions credits would have across the whole agricultural sector. In earlier analyses of the economics of agricultural feedstocks for energy production, one of the major issues uncovered (Tyner et al., 1979) was that program adoption caused increasing prices of food to traditional consumers and reductions in export earnings. Crops for food and crops for fuel are competitors. Expanding energy crops for greenhouse gas emission mitigation would reduce crops for food. Food and land prices would likely rise. A total accounting look at all aspects of the issue is needed. The costs and benefits of alterations in the traditional agricultural sector versus the costs and benefits of using land to meet obligations under the Kyoto Protocol must be carefully weighed. Shifts in the distribution of income between agricultural 
producers and consumers may occur. A comprehensive evaluation needs to add in the costs and benefits of the negative and positive externalities associated with carbon sequestration, including, ideally, the costs and benefits of a changing climate.

\subsection{OTHER CONSIDERATIONS}

There are a large number of institutions and or programs that may be needed to support carbon sequestration efforts. These include

a) Market mechanisms that support trade in emissions credits;

b) Groups that provide insurance against sequestration shortfalls;

c) Brokers who aggregate individual carbon contributions to facilitate trades and offer risk reducing sequestration portfolios;

d) Organizations and procedures to document and certify emissions reductions; and

e) Educational programs that facilitate adoption and train farmers and others in the use of more complicated strategies.

All of these must be able to deal with thousands of potential providers at manageable levels of administrative costs.

There is also internationally expressed concern about issues of equity, "environmental imperialism", and buying one's way out of national commitments. Do there need to be international mechanisms to guard the interests of Parties with fewer financial resources or poorer access to information. One can argue that trading of carbon emissions permits will occur in a free and open market, with transactions between willing partners; but there may need to be mechanisms to insure that economic interests do not overrun social interests or equity concerns. This may be especially true for issues of carbon sequestration because of the long-term commitments and implications involved.

Finally we should note that there may well be needs to coordinate carbon sequestration policy with many other policy endeavors. 


\section{Summary and Conclusions}

Whether, and to what extent, carbon will be sequestered in forest and agricultural soils will depend on issues of practical economics and policy design. In some cases, carbon can be enhanced through small alterations in current land uses, perhaps to the benefit of all. In other cases, land for carbon mitigation may displace current land-use practices. In yet other cases, incentives may simply be insufficient to stimulate changes in land-use practices. In general the establishment of a carbon trading market should provide additional economic opportunities for landholders and rural communities. The big questions are:

1. Will agricultural soils be approved as a means to meet greenhouse gas emissions commitments?

2. Will the incentives be there so that landowners will adopt appropriate practices in their own best interests?

3. Can an emissions trading program be designed so the carbon that is paid for remains sequestered for as long as needed?

4. Can incentives be designed so that countervailing leakages of carbon are not stimulated? In that vein, how does one avoid paying people who would never have done countervailing land transfers and how does one avoid major private property rights issues?

5. How will emissions reduction be integrated into the total fabric of agricultural policy?

6. Are there agricultural or forestry practices that would increase net carbon storage in soils with positive, or small negative, impacts on productivity along with net positive externality effects?

7. How will international trading come into play?

8. What is the relative merit of soil carbon sequestration in terms of other possible agricultural actions that could be undertaken within the context of an emissions reduction program?

9. How will uncertainty in the amounts and rates of sequestration be taken into account?

Addressing these questions implies a multidimensional research agenda examining not only the technological possibilities for carbon sequestration, but also the design and structure of incentive and policy 
programs to stimulate sequestration activity. Such work must consider not only the direct effects of incentives and policies on the target activities, but also the indirect effects across the economy that may lead to unexpected external costs, benefits, or sequestration offsets.

\section{Acknowledgements}

We acknowledge our debt to other people who have contributed to the ideas presented here. We particularly thank Darius Adams, Richard Adams, Ralph Alig, Mac Callaway, William Hohenstein, Bernhard Schlamadinger, and Stephen Winnett, along with many others, for contributing to our collective knowledge over the years. Norman Rosenberg, John Bennett, John McClelland, Debra Reed, Ronald Sands and two anonymous journal reviewers contributed useful comments on this paper. 


\section{References}

Adams, R. M., Chang, C. C., McCarl, B. A., and Callaway, J. M.: 1992, 'The Role of Agriculture in Climate Change: A Preliminary Evaluation of Emission Control Strategies', in J. M. Reilly and Anderson, M. (eds.), Economics Issues in Global Climate Change: Agriculture, Forestry, and Natural Resources, Westview Press, pp. 273-287.

Antle, J.M.: 2000. "Economic Feasibility of Using Soil Carbon Sequestration Policies and Markets to Alleviate Poverty and Enhance Sustainability of the World's Poorest Farmers." Paper presented at the Expert Workshop on Carbon Sequestration, Sustainable Agriculture, and Poverty Alleviation held at the World Meteorological Organization (WMO), Geneva, Switzerland, August 31, 2000. http://www.climate.montana.edu/.

Antle, J.M. and Mooney, S.: 1999. "Economics and Policy Design for Soil Carbon Sequestration in Agriculture.” Research Discussion Paper No. 36, Trade Research Center, Montana State UniversityBozeman, October. http://www.climate.montana.edu/.

Bolin, B., 1998, 'The Kyoto Negotiations on Climate Change: A Science Perspective', Science 279, 330-331.

Canada, 1998, in UNFCCC, Subsidiary Body for Scientific and Technological Advice, Report FCCC/SBSTA/1998/Misc.6/Add1, Additional submissions by Parties, at http://fccc.de.

Council of Economic Advisers, Executive Office of the President, 1998, 'The Kyoto Protocol and the President's Policies to Address Climate Change: Administration Economic Analysis', July.

Energy Information Administration, U.S. Department of Energy: 1998, 'Impacts of the Kyoto Protocol on U.S. Energy Markets and Economic Activity', SR/OIAF/98-03, October.

Epplin, F.M., and Al-Sakkaf., G.A.: 1995 "Risk-Efficient Tillage Systems and Program Participation Strategies for Land Subject to Conservation Compliance." Rev. of Agr. Econ. 17:311-21

IPCC, 2000, Land Use, Land-use Change, and Forestry; Intergovernmental Panel on Climate Change, a Special Report of the IPCC, Cambridge University Press, Cambridge, UK.

Klemme, R.M. (1985) "A Stochastic Dominance Comparison of Reduced Tillage Systems in Corn and Soybean Production Under Risk." Amer. J. Agr. Econ. 67:550-7.

Kyoto Protocol to the United Nations Framework Convention on Climate Change: 1998, 'Climate Change Secretariat', UNFCCC, http://www.cop3.de, March.

Lal, R., Kimble, J. M., Follett, R. F., and Cole, C. V.: 1998, 'The Potential of U.S. Cropland to_Sequester Carbon and Mitigate the Greenhouse Effect', Sleeping Bear Press, Inc., Chelsea MI, 128 pp.

Magleby, R., Sandretto, C. Crosswhite, W. and Osborn, C.T.. 1995. Soil Erosion and Conservation in the United States - An Overview. USDA, ERS, Agric. Info. Bull. No. 718

Manne, A. and Richels, R. G.: 1998, 'The Kyoto Protocol: A Cost-Effective Strategy for Meeting Environmental Objectives?', unpublished manuscript, Stanford University, July. 
Marland, G. and Schlamadinger, B.: 1997, 'Forests for Carbon Sequestration or Fossil Fuel Substitution A Sensitivity Analysis’, Biomass and Bioenergy 13, 389-397.

McCarl, B. A. and Schneider, U.: 1999, 'Curbing Greenhouse Gases: Agriculture's Role', Choices, first quarter, pp. 9-12.

McCarl, B.A. and Schneider, U.: 2000a, "Agriculture's Role in a Greenhouse Gas Emission Mitigation World: An Economic Perspective", Review of Agricultural Economics, 22 134-159.

McCarl, B.A. and Schneider, U.: 2000b, "Economic Potential of Biomass for Greenhouse Gas Emission Reductions: Comparative role in Agriculture", Proceedings of conference on Sustainable Energy: New Challenges for Agriculture and Implications for Land Use Wageningen University, The Netherlands.

McCarl, B. A.: 1998, 'Carbon Sequestration via Tree Planting on Agricultural Lands: An Economic Study of Costs and Policy Design Alternatives', Unpublished Report, Texas A\&M University, College Station on the web page agrinet.tamu.edu/mccarl.

McCarl, B. A., Gowen, M., and Yeats, T.: 1997, 'An Impact Assessment of Climate Change Mitigation Policies and Carbon Permit Prices on the U.S. Agricultural Sector', Climate Change Policies and Programs Division, USEPA, Washington, DC,

Metting, F.B. Smith, J. L., and Amthor, J. S., 2000, Science Needs and New Technology for Soil Carbon Sequestration, this volume.

Pierzynski, G.M., Sims, J. T., and Vance, G.F. 1994. Soils and Environmental Quality. Lewis Publishers, CRC Press, Boca Raton FL.

Post, W. M., Izaurralde, R. C., Mann, L. K., and Bliss, N.: 2000, 'Monitoring and Verifying Soil Organic Carbon Sequestration', this volume.

Schneider, U. 2000, Agricultural Sector Analysis on Greenhouse Gas Emission Mitigation in the United States, Unpublished PhD Thesis, Department of Agricultural Economics, Texas A\&M University.

Trimble, S.W. and Crosson, P. 2000. "U.S. Soil Erosion Rates - Myth and Reality." Science Vo. 289, July 14 , pp. $248-250$.

Tyner, W., Abdallah M., Bottum, C., Doering, O., McCarl, B.A., Miller, W., Liljedahl, B., Peart R., Richey, C., Barber, S., and Lechtenberg, V.: 1979, 'The Potential of Producing Energy From Agriculture', Purdue School of Agriculture, Final Report to Office of Technology Assessment, US Congress.

United Nations: 1992, 'Framework Convention on Climate Change', United Nations Environment Programme Information Unit for Conventions, http://www.unep.ch.

Weyant, J. and Hill, J.: 1999 "Introduction and Overview" Special Issue: The Costs of the Kyoto Protocol: A Multi Model Evaluation: Energy Journal."

Wigley, T. M. L.: 1998, 'The Kyoto Protocol: $\mathrm{CO}_{2}, \mathrm{CH}_{4}$ and Climate Implications', Geophys. Res. Letters 25, 2285-2288.

Williams, J.R., Llewelyn, R.V. and Barnaby G.A:1990. "Risk Analysis of Tillage Alternatives With 
Government Programs." Amer. J. Agr. Econ. 72:172-81. 